\title{
Activation of Co Fischer-Tropsch Catalyst: Exploring Co Valence State under Different Reduction Conditions Using STEM-EELS
}

\author{
Ofentse A. Makgae ${ }^{*}$, Arthur N. Moya ${ }^{1}$, Benzhen $\mathrm{Yao}^{2}$, Manfred E. Schuster ${ }^{3}$, Peter P. Edwards ${ }^{2}$, \\ Emanuela Liberti ${ }^{1}$ and Angus I. Kirkland ${ }^{1,4}$ \\ 1. Department of Materials, University of Oxford, Parks Roads, Oxford, United Kingdom. \\ 2. King Abdulaziz City for Science and Technology - Oxford Centre of Excellence in Petrochemicals, \\ Inorganic Chemistry Laboratory, Department of Chemistry, University of Oxford, South Parks Road, \\ Oxford, United Kingdom. \\ 3. Johnson Matthey Technology Centre, Reading, United Kingdom. \\ 4. electron Physical Science Imaging Centre, Diamond Light Source Ltd., Didcot, United Kingdom. \\ * Corresponding author: ofentse.makgae@materials.ox.ac.uk
}

Cobalt (Co) is rarely available as a pure reduced metal for industrial Fischer-Tropsch Synthesis (FTS) due to its tendency to oxidise rapidly [1]. As a result, the production of active metallic Co is typically achieved through the reduction of spinel cobalt oxide $\left(\mathrm{Co}_{3} \mathrm{O}_{4}\right)$ in the FTS catalytic reactor prior to the synthesis. Occasionally, depending on the reactor temperature and the composition of the reducing atmosphere, $\mathrm{Co}_{3} \mathrm{O}_{4}$ does not fully reduce to active metallic $\mathrm{Co}$, resulting in a catalyst with mixed Co valence states, crystallographic phases and surface terminations [2]. In this case, the activity of the catalyst is reduced while the selectivity towards methane is increased [3]. Electron energy loss spectroscopy (EELS) can be used to obtain information about the valence states of reduced Co from the Co- $\mathrm{L}_{3,2}$ edge fine structure, and the oxygen $\mathrm{K}$ edge [4]. Specifically the Co valence state varies according to the $\mathrm{L}_{3} / \mathrm{L}_{2}$ peak intensity ratio, the $\mathrm{L}_{3,2}$ peak-to-peak energy resolution, and the onset energy loss of the $\mathrm{L}_{3}$ peak and O-K pre-peak $[5,6]$. Hence, these parameters can be used to measure quantitatively the oxidation state of the catalyst after reduction. Herein, we investigate the ex-situ reduction of $\mathrm{Co}_{3} \mathrm{O}_{4}$ nanoparticles supported on hollow carbon spheres as the catalyst precursor for the FTS under $\mathrm{H}_{2}$ gas and syngas at $350{ }^{\circ} \mathrm{C}$. The reduced Co catalyst was studied in an aberration corrected analytical scanning transmission electron microscope (JEOL ARM200F) fitted with a Gatan GIF Quantum 965 ER, at $200 \mathrm{kV}$ using a semi-convergence angle of $14 \mathrm{mrad}$ for simultaneous acquisition of both EELS and ADF signals. Figure 1 shows the EELS spectra and the associated $\mathrm{O}-\mathrm{K}$ edge (red) and $\mathrm{Co}_{-} \mathrm{L}_{3,2}$ edge (green) elemental maps of the pristine, $350{ }^{\circ} \mathrm{C}$ hydrogen reduced, and $350{ }^{\circ} \mathrm{C}$ syngas reduced Co catalyst. These results suggest that syngas achieves a higher degree of reduction than $\mathrm{H}_{2}$ gas at $350{ }^{\circ} \mathrm{C}$. This is reflected in Figure 1 (a) by the shift of the Co$\mathrm{L}_{3}$ edge to lower energy losses with decreasing Co valence state and the intensity of the O-K edge prepeak (peak ' $\alpha$ ' in Figure 1(a)), which decreases with decreasing Co valence state. Furthermore, a higher degree of reduction is indicated on the elemental maps by the intense $\mathrm{Co}_{0} \mathrm{~L}_{3,2}$ edge signal across the syngas reduced catalyst particle (Figure 1(d)) compared to the hydrogen reduced catalyst particle (Figure 1(c)). In this contribution we will discuss the most effective routes for the activation of cobalt FTS catalysts where maximum reduction is achieved.

\section{References:}

[1] D Schanke et al., Energy \& Fuels 10 (1996), p. 867.

[2] AY Khodakov et al., J. Catal. 168 (1997), p. 16.

[3] MK Gnanamani et al., Catal. Today 215 (2013), p. 13.

[4] Y Zhao et al., J. Appl. Phys. 108 (2010), p. 63704.

[5] DH Pearson, CC Ahn and B Fultz, Phys. Rev. B 47 (1993), p. 8471. 
[6] Z Zhang, Ultramicroscopy 107 (2007), p. 598.

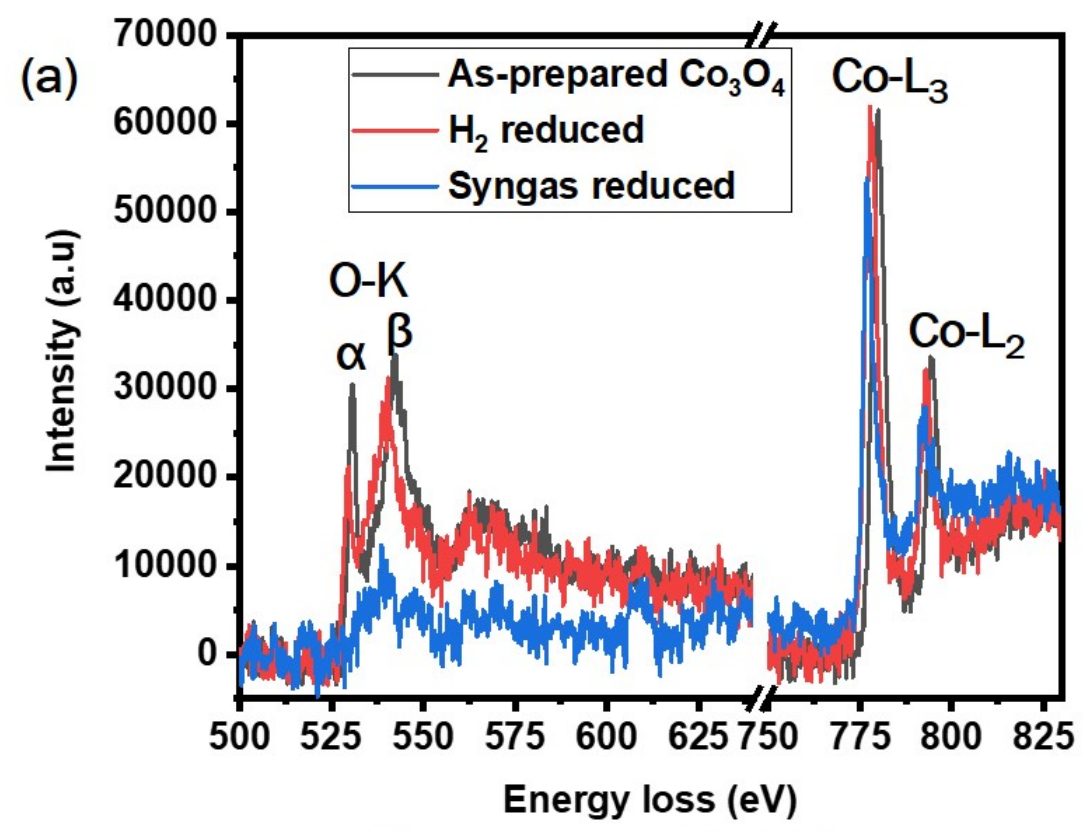

(b) as-prepared

(c) $\mathrm{H}_{2}$ red.

(d) Syngas red.

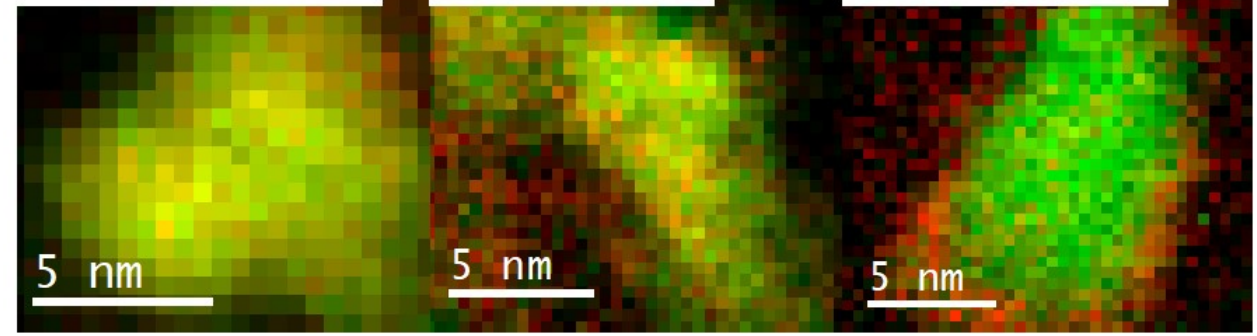

Figure 1. (a) EELS spectra of as-prepared $\mathrm{CO}_{3} \mathrm{O}_{4}$ (black), $350{ }^{\circ} \mathrm{C} 10 \%$ (v/v) hydrogen reduced (red), and $350{ }^{\circ} \mathrm{C}$ syngas (1:2 CO:H2) reduced catalyst (blue). (b), (c), and (d) are EELS elemental maps of asprepared, hydrogen reduced, and syngas reduced Co catalyst, respectively. Red shows the O-K edge signal and green the $\mathrm{Co}_{-} \mathrm{L}_{3,2}$ edge signal. 